\title{
Subregional, Dendritic Compartment, and Spine Subtype Specificity in Cocaine Regulation of Dendritic Spines in the Nucleus Accumbens
}

\author{
Dani Dumitriu, ${ }^{1 \star}$ Quincey LaPlant, ${ }^{1 \star}$ Yael S. Grossman, ${ }^{1}$ Caroline Dias, ${ }^{1}$ William G. Janssen, ${ }^{1}$ Scott J. Russo, ${ }^{1}$ \\ John H. Morrison, ${ }^{1,2}$ and Eric J. Nestler ${ }^{1}$ \\ ${ }^{1}$ Fishberg Department of Neuroscience and Friedman Brain Institute and 2Department of Geriatrics and Palliative Care, Mount Sinai School of Medicine, \\ New York, New York 10029
}

\begin{abstract}
Numerous studies have found that chronic cocaine increases dendritic spine density of medium spiny neurons in the nucleus accumbens (NAc). Here, we used single-cell microinjections and advanced 3D imaging and analysis techniques to extend these findings in several important ways: by assessing cocaine regulation of dendritic spines in the core versus shell subregions of NAc in the mouse, over a broad time course ( $4 \mathrm{~h}, 24 \mathrm{~h}$, or $28 \mathrm{~d}$ ) of withdrawal from chronic cocaine, and with a particular focus on proximal versus distal dendrites. Our data demonstrate subregion-specific, and in some cases opposite, regulation of spines by cocaine on proximal but not distal dendrites. Notably, all observed density changes were attributable to selective regulation of thin spines. At $4 \mathrm{~h}$ after injection, the proximal spine density is unchanged in the core but significantly increased in the shell. At $24 \mathrm{~h}$, the density of proximal dendritic spines is reduced in the core but increased in the shell. Such downregulation of thin spines in the core persists through $28 \mathrm{~d}$ of withdrawal, whereas the spine density in the shell returns to baseline levels. Consistent with previous results, dendritic tips exhibited upregulation of dendritic spines after $24 \mathrm{~h}$ of withdrawal, an effect localized to the shell. The divergence in regulation of proximal spine density in NAc core versus shell by cocaine correlates with recently reported electrophysiological data from a similar drug administration regimen and might represent a key mediator of changes in the reward circuit that drive aspects of addiction.
\end{abstract}

\section{Introduction}

GABAergic medium spiny neurons (MSNs), the predominant cells of the nucleus accumbens (NAc), play a major role in drug addiction. In response to chronic cocaine, MSNs undergo dramatic, long-lasting adaptations on an epigenetic, transcriptional, morphologic, and electrophysiologic level (Kalivas, 2009; Russo et al., 2010; LaPlant and Nestler, 2011). MSNs reside in two functionally and anatomically distinct subregions of the NAc: the core and shell. These two populations of MSNs have different afferent and efferent projections (Zahm, 2000) and are thought to play different roles in shaping reward behavior (Ito et al., 2004). Recent work in brain slices has identified that the core and shell have opposite cocaine-induced adaptations in intrinsic excitability (Kourrich and Thomas, 2009). Despite this, cocaine-induced upregulation of dendritic spines is generally thought to occur in concert within the two subregions, perhaps because most studies have either explicitly focused on one subregion (Robinson and Kolb, 1999; Shen et al., 2009; Kiraly et al., 2010) or have combined

Received Nov. 14, 2011; revised March 15, 2012; accepted March 19, 2012.

Author contributions: D.D., Q.L., S.J.R., J.H.M., and E.J.N. designed research; D.D., Q.L., Y.S.G., C.D., and W.G.J. performed research; D.D., Q.L., and Y.S.G. analyzed data; D.D., Q.L., and E.J.N. wrote the paper.

*D.D. and Q.L. contributed equally to this work.

Correspondence should be addressed to Dr. Eric Nestler, Fishberg Department of Neuroscience and Friedman

Brain Institute, Mount Sinai School of Medicine, Icahn Medical Institute, Floor 10, Room 10-23, 1425 Madison Avenue, New York, NY 10029. E-mail: eric.nestler@mssm.edu.

DOI:10.1523/JNEUROSCI.5718-11.2012

Copyright $\odot 2012$ the authors $\quad 0270-6474 / 12 / 326957-10 \$ 15.00 / 0$ core/shell data (Lee et al., 2006; Pulipparacharuvil et al., 2008; Russo et al., 2009).

Furthermore, previous reports have focused on distal dendrites, quantifying spines at or near their tips. This emphasis is primarily based on an early report (Li et al., 2003) showing that long-term psychostimulant-induced spine changes occur in distal but not proximal dendrites. Recently, there has been a growing awareness of functional differences between dendritic compartments (Spruston, 2008); for example, proximal spines are primarily involved in local feedforward excitation, whereas distal spines are associated with nonlinear events, such as NMDA spikes in pyramidal neurons (Larkum et al., 2009) and generation of prolonged "up states" in NAc MSN tips (Plotkin et al., 2011). This added potential for dichotomy in drug-induced changes in different dendritic compartments, together with the notable difference in our model versus that studied by Li et al. [male mice treated with cocaine in our model versus female rats treated with amphetamine in (Li et al., 2003)], prompted us to focus on the relatively ignored proximal dendrites.

To date, dendritic spine quantification has primarily relied on manual counts of projected 2D images. Shen et al. (2009) were the first to use 3D spine counting methods in MSNs from cocaine-treated animals, demonstrating not only a dramatic density difference between 2D Golgi and 3D DiI methods but also a selective bias against thin spines in $2 \mathrm{D}$ counts. This is a crucial disadvantage in light of the growing awareness of the importance of thin spines in addiction (LaPlant et al., 2010) and other models 
A

NAc microinjections

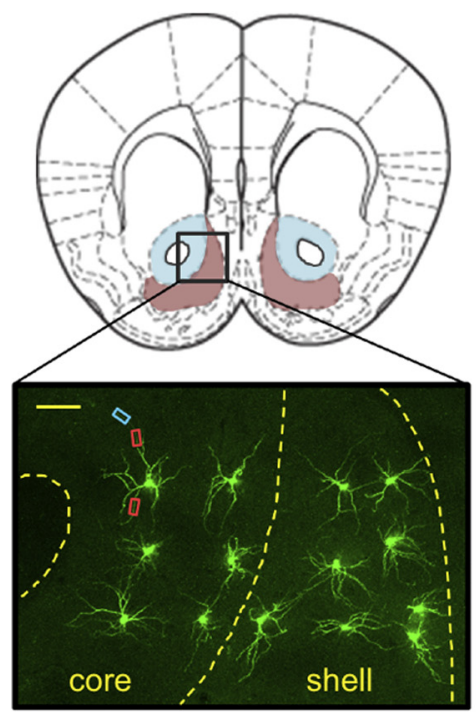

B

Imaging and deconvolution
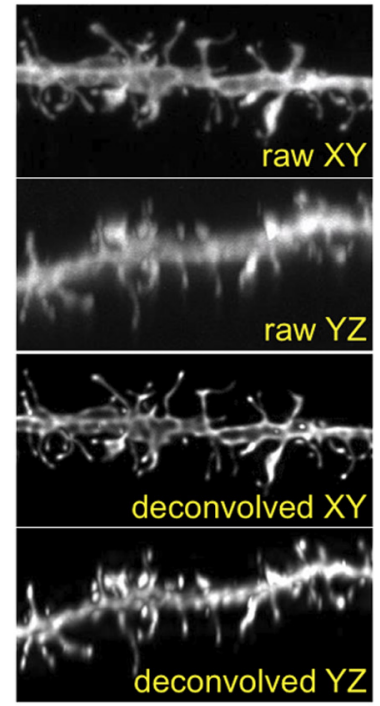

C

\section{D spine analysis}

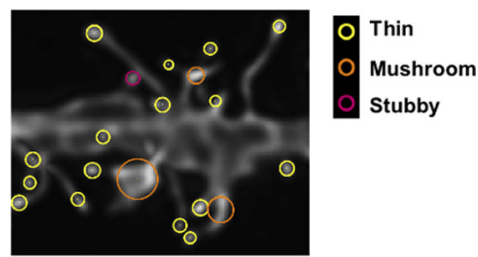

D

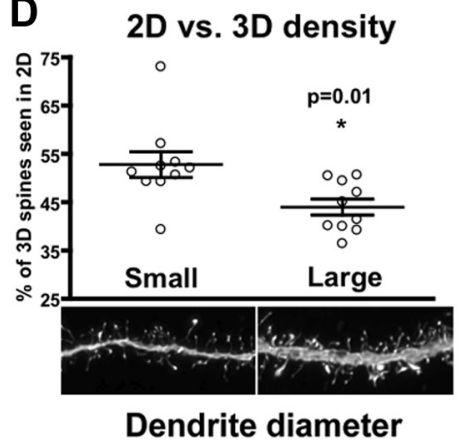

Figure 1. Experimental design. $A, A 10 \times$ image of NAc core and shell microinjected neurons with corresponding diagram from the Paxinos mouse brain atlas (Paxinos and Franklin, 2001). Medial NAc neurons were microinjected $+1.42 \pm 0.25 \mathrm{~mm}$ anterior to bregma. Boxes represent the subcellular location of dendritic imaging, with red boxes representing proximal dendrites and blue box representing a dendritictip. Scale bar, $100 \mu \mathrm{m}$. B, Projections of a high-resolution 3D confocal stack before and after deconvolution in the $x-y$ and $y-z$ direction. C, NeuronStudio 3 D automatic identification, measurement, and classification of spines: yellow, thin; orange, mushroom; purple, stubby. $\boldsymbol{D}$, Ten small-diameter and 10 large-diameter dendrites were analyzed semiautomatically with NeuronStudio and then manually by counting visible spines in $2 \mathrm{D}$ projected images. The percentage of $3 \mathrm{D}$ spines visible in $2 \mathrm{D}$ projected images is plotted, with circles indicating individual dendrites and lines indicating mean \pm SEM. There is a significant difference between the two groups ( $p=0.01$ ), pointing to the difficulty in comparing $2 \mathrm{D}$ and $3 \mathrm{D}$ methods. ${ }^{*} p<0.05$.

of plasticity (Kasai et al., 2010). Therefore, to fully appreciate the morphological adaptations that occur in NAc core and shell after chronic cocaine administration, we analyzed 118,940 spines in 3D, using single-cell microinjections in fixed brain sections from mice after $4 \mathrm{~h}, 24 \mathrm{~h}$, or $28 \mathrm{~d}$ of withdrawal. Our findings, alongside other recent findings that differ from early reports (Shen et al., 2009; Dobi et al., 2011), highlight multilevel dichotomies in spine regulation and indicate the importance of careful attention to individual components within the microcircuit.

\section{Materials and Methods}

Animals and cocaine injections. Adult male C57BL/6J mice (The Jackson Laboratory) were habituated in our facility 1 week before experimentation and housed on a $12 \mathrm{~h}$ light/dark cycle with access to food and water ad libitum. All animal experiments were approved by the Institutional Animal Care and Use Committee of Mount Sinai School of Medicine. For experiments looking at 4 and $24 \mathrm{~h}$ time points, we used a standard cocaine injection procedure: seven daily intraperitoneal injections of 20 $\mathrm{mg} / \mathrm{kg}$ cocaine (Renthal et al., 2009; LaPlant et al., 2010). All mice were injected in their home cages between Zeitgeber time 10 and 12. For experiments evaluating $28 \mathrm{~d}$ of withdrawal, we used the same cocaine dose but daily injections for $28 \mathrm{~d}$ (Robinson and Kolb, 1999; Lee et al., 2006; LaPlant et al., 2010). Controls were injected with saline in tandem with their experimental group counterparts. Because of the large total number of animals used in the study, subjects for each of the three experiments ( $4 \mathrm{~h}, 24 \mathrm{~h}$, and $28 \mathrm{~d}$ ) were processed at different times. Therefore, absolute values for spine morphometrics of saline controls and cocaine-injected subjects for each of the three experiments should not be directly compared because of potential differences resulting from use of multiple animal batches.

Single-cell microinjection. A detailed description of our protocol was published recently (Dumitriu et al., 2011). Briefly, mice were perfused with $4 \%$ paraformaldehyde and $0.125 \%$ glutaraldehyde in $0.1 \mathrm{M}$ phosphate buffer. Brains were transferred into $0.14 \mathrm{M}$ phosphate buffer with $0.9 \%$ saline and sectioned into $250 \mu \mathrm{m}$ slices. Cells in NAc core and shell were impaled with a micropipette containing $5 \%$ Lucifer yellow (Invit- rogen), injected with 1-10 nA of current, and mounted for confocal microscopy. Because of the heterogeneous nature of the NAc, great care was taken to identify the same subregion of the core and shell in each animal. In the anteroposterior axis, we chose the section closest to bregma $+1.42 \mathrm{~mm}$. In the rare event that we needed more than one section to get the minimum of six core and six shell cells, we performed additional injections in the section immediately anterior or immediately posterior to the reference section. Thus, all sampled cells are located $+1.42 \pm 0.25 \mathrm{~mm}$ anterior to bregma. In the dorsoventral axis, we chose the medial portion of the NAc, which we defined by the region between two imaginary lines drawn between the dorsal and ventral borders of the left and right anterior limb of the anterior commissure (Fig. $1 \mathrm{~A}$ ).

Confocal imaging. Proximal dendrites were defined as the middle portions of terminal dendrites, specifically avoiding the initial aspiny portion and the distal $30 \mu \mathrm{m}$ (Fig. $1 \mathrm{~A}$, red boxes). On average, proximal dendrites were located $51 \pm 1 \mu \mathrm{m}$ from the soma, with a range of $24-100$ $\mu \mathrm{m}$. Reducing the range of distances from the soma was limited by the effort of finding dendrites that are parallel to the plane of the section to minimize the imaging time (dendrites that are perpendicular to the plane of the section require significantly larger $z$-stacks). Distal dendrites were defined as the most distal $30 \mu \mathrm{m}$, i.e., the tips of dendrites (Fig. $1 \mathrm{~A}$, blue box). $z$-Stacks were acquired using a $0.033 \times 0.033 \times 0.33 \mu \mathrm{m}^{3}$ voxel size on an inverted Carl Zeiss LSM 710 confocal microscope equipped with a $100 \times 1.4$ numerical aperture oil-immersion objective (Fig. $1 B$ ). For proximal dendrites, on average 12 dendrites from six neurons were imaged for each animal (i.e., two dendrites per cell; average total dendritic length, $738 \pm 22 \mu \mathrm{m} /$ animal; $n=4-8$ animals per group). For distal dendrites, on average six dendrites from six neurons were imaged for each animal (i.e., one dendritic tip per cell; average total dendritic length, $365 \pm 10 \mu \mathrm{m} /$ animal; $n=4-8$ animals per group). The vast majority of distal dendrites were imaged from the same cells that were included in the proximal dendrite analysis.

Spine analysis. Images were deconvolved using AutoDeblur (MediaCybernetics; Fig. $1 \mathrm{~B}$ ), and spine analysis was performed using the semiautomated software NeuronStudio (http://research.mssm.edu/cnic/ tools-ns.html), which analyzes dendritic length, dendritic width, spine 
number, and spine head diameter in 3D (Fig. 1C). NeuronStudio further classifies spines into three major morphologic types: thin, mushroom, and stubby (Fig. 1C). After NeuronStudio processing, a human operator, blinded to the condition, verified that all 118,940 spines from 1315 dendrites had been appropriately identified and manually corrected any errors in spine identification. Because each of the three experiments $(4 \mathrm{~h}$, $24 \mathrm{~h}$, and $28 \mathrm{~d}$ ) was processed at different times, direct comparison of absolute values for spine densities for saline and control groups cannot be made between different experiments.

The significant difference in spine density counts between 2D methods, such as Golgi, and 3D methods, such as serial section electron microscopy, have been recognized for many years (Hama et al., 1989). We recently showed that our 3D spine counting method using highresolution confocal microscopy, deconvolution, and NeuronStudio yields spine morphometric measurements that precisely match data obtained with the gold standard of serial section electron microscopy, albeit in a fraction of the time (Dumitriu et al., 2011). The relationship between $2 \mathrm{D}$ and $3 \mathrm{D}$ spine density counts has been shown previously to be more than a mere difference in magnitude (Vecellio et al., 2000). The percentage of true spines observed in a 2D image depends on factors such as dendritic diameter (thicker dendrites conceal higher proportions of spines) and spine length (shorter spines are less likely to protrude from the axis of the dendrite). To directly and experimentally characterize one aspect of the relationship between $2 \mathrm{D}$ and $3 \mathrm{D}$ counts in our model, we selected 10 large-diameter dendrites (average diameter, $1.1 \pm 0.02 \mu \mathrm{m}$ ) and 10 small-diameter dendrites (average diameter, $0.50 \pm 0.01 \mu \mathrm{m}$ ) and compared our $3 \mathrm{D}$ semi-automated counts with $2 \mathrm{D}$ counts performed on $Z$-projected images of the same dendrites (Fig. 1D). Consistent with previous results (Vecellio et al., 2000), we found that the proportion of $3 \mathrm{D}$ spines seen in $2 \mathrm{D}$ projected images is significantly higher in smalldiameter dendrites ( $53 \pm 3$ vs $44 \pm 2 \%$ in small- versus large-diameter dendrites, $p=0.01$; Fig. $1 D$ ). Thus, two dendrites of different thickness but with the same 3D density could appear to have up to a $20 \%$ difference with $2 \mathrm{D}$ analysis (the difference between 44 and 53\%). As an example, let us assume that an animal has an average density of 3 spines $/ \mu \mathrm{m}$ and an average dendrite diameter of $1 \mu \mathrm{m}$. The animal then receives a pharmacological manipulation that decreases spine density by $10 \%$ and decreases dendrite diameter to $0.5 \mu \mathrm{m}$. If the spine density is obtained using $3 \mathrm{D}$ counting, the animal will be recorded to have 3.00 spines $/ \mu \mathrm{m}$ before and 2.70 spines/ $\mu \mathrm{m}$ after the manipulation. However, if the density is obtained using $2 \mathrm{D}$ counting, the animal will be recorded as having 1.32 spines/ $\mu \mathrm{m}$ before ( $44 \%$ of 3.00 spines/ $\mu \mathrm{m}$ in dendrite of $1 \mu \mathrm{m}$ diameter are visible) and 1.43 spines $/ \mu \mathrm{m}$ after ( $53 \%$ of 2.70 spines $/ \mu \mathrm{m}$ in dendrite of $0.5 \mu \mathrm{m}$ diameter are visible) the manipulation. Thus, the animal will be recorded as having a $10 \%$ decrease in density with the 3D method and an $8 \%$ increased spine density using the $2 \mathrm{D}$ method. The $2 \mathrm{D} / 3 \mathrm{D}$ relationship becomes much more complex when spine length is also taken into consideration and is beyond the scope of our discussion here. Our intention is not to fully characterize the origin of the difference in results obtained with $2 \mathrm{D}$ versus $3 \mathrm{D}$ methods but rather to point out that only limited comparisons can be made between our studies and previous studies using 2D methods, such as Golgi.

Statistical analysis. Excel, Matlab, and GraphPad Prism were used. Total and subtype spine densities were calculated by dividing the total number of spines by the length of the dendritic segment. The average proximal or distal spine density and dendrite diameter for each neuron was then calculated, followed by the total average density/diameter for each brain region in each animal. Group data are reported as mean \pm SEM using each animal average in a given group. Cumulative distributions are unsmoothed and contain all dendrites or spines in a given group. Distribution differences were evaluated using the KolmogorovSmirnov (K-S) test. Binned data were generated first by animal and then by group. Statistical differences for group data were measured using two-way Student's $t$ test. Statistical differences for spine subtype density and size (binned data) were measured using two-way ANOVA and twoway repeated-measures ANOVA, respectively, and the post hoc tests were performed using the Bonferroni method.

\section{Results}

Chronic cocaine oppositely regulates proximal dendritic spine density in NAc core versus shell

Individual MSNs from the NAc core and shell of mice were microinjected with Lucifer yellow at 4 or $24 \mathrm{~h}$ after seven daily cocaine or saline injections (Fig. 1A). High-resolution confocal $z$-stacks of proximal dendrites (for details, see Materials and Methods) were obtained and deconvolved (Fig. $1 B$ ). Unbiased spine morphometric analysis in 3D was then performed semiautomatically by a blind experimenter using NeuronStudio (Rodriguez et al., 2008) (Fig. 1C), a method shown recently to yield data highly congruent with serial section electron microscopy for morphometric analysis of spines (Dumitriu et al., 2011).

At $4 \mathrm{~h}$, we observed no significant difference in the average spine density ( $t$ test, $p=0.56$ ) or distribution of proximal spine densities plotted as a cumulative frequency (K-S test, $p=0.7$ ) in the NAc core (Fig. $2 A$ ). However, in the shell of these same animals, there was a significant increase in average proximal spine density ( $10 \%$ increase from $2.58 \pm 0.05$ to $2.83 \pm 0.09$ spines $/ \mu \mathrm{m}, t$ test, $p=0.04)$ and a significant shift in the distribution of densities along individual dendrites (K-S test, $p=0.007$ ) (Fig. $2 B$ ). Interestingly, the cumulative distribution in Figure $2 B$ indicates that the initial addition of new spines is not random. Low-density dendrites seem unaffected by cocaine (black and red lines are superimposed below the 50th percentile), suggesting that the new spines are preferentially added with circuit specificity, perhaps by activitydependent spine consolidation.

At $24 \mathrm{~h}$ after the last injection, the divergence in the regulation by cocaine of proximal spine density in NAc core versus shell was even more striking (Fig. 2C,D). The increase in MSN proximal spine density in the shell was enhanced (16\% increase from $2.67 \pm 0.10$ to $3.09 \pm 0.08$ spines $/ \mu \mathrm{m}, t$ test, $p=0.008)$ and extended to all dendrites as indicated by a generalized rightward shift in the cumulative frequency of spine density of dendrites from cocaine-injected mice (K-S test, $p=2 \times 10^{-5}$ ) (Fig. $2 D$ ). Conversely, in the core, there was a significant decrease in proximal spine density ( $10 \%$ decrease from $3.81 \pm 0.13$ to $3.41 \pm 0.12$ spines $/ \mu \mathrm{m}, t$ test, $p=0.04$ ), as well as a corresponding generalized leftward shift in the cumulative frequency of spine density of individual dendrites (K-S test, $p=0.03$ ) (Fig. 2D).

\section{Chronic cocaine increases proximal dendritic diameter in the NAc shell but not core}

Through its actions on input resistance, dendritic diameter plays a major role in affecting how signals at the synapse are ultimately propagated to the soma to initiate action potentials. Little is known about how changes in spine density influence dendrite diameter and vice versa. In light of the dramatic effects of cocaine on proximal spine density in NAc (Fig. 2A-D), we assessed dendritic diameter using NeuronStudio. The mean diameters were obtained for the 709 dendrites that were imaged and analyzed by a blind operator for the above spine density measurements. We found the average proximal dendrite diameter to be significantly increased in the shell after $4 \mathrm{~h}$ (Fig. $2 \mathrm{E}, 7 \%$ increase from $0.74 \pm$ 0.02 to $0.79 \pm 0.01 \mu \mathrm{m}, t$ test, $p=0.04$ ) or $24 \mathrm{~h}$ (Fig. $2 F, 8 \%$ increase from $0.75 \pm 0.01$ to $0.81 \pm 0.03 \mu \mathrm{m}, t$ test, $p=0.04$ ) of cocaine withdrawal. No significant change in proximal diameter was observed in the core at either time point (Fig. $2 E, F, t$ test, $p=$ 0.10 and $p=0.29$, respectively). 
Cocaine regulation of NAc proximal spine density is restricted to a selective and opposite effect on thin dendritic spines

Do the above changes in NAc proximal spine density reflect a nonspecific regulation of all types of dendritic spines or does cocaine affect specific subtypes? To answer this question, we took advantage of the NeuronStudio unbiased classification of spines into three well described morphologic subtypes: thin, mushroom, and stubby. As noted previously, NeuronStudio's measurement of dendritic spine size - the basis for classification into subtypes - has been validated by comparison with serial section electron microscopy (Dumitriu et al., 2011). We found that all of the observed effects on spine density could be attributed to a selective gain or loss of thin spines.

Consistent with the observation that overall proximal spine density was unchanged in the NAc core at $4 \mathrm{~h}$ of cocaine withdrawal, we observed no significant difference in any of the three spine types in this group [Fig. 3A, two-way ANOVA, no interaction, drug effect (cocaine, saline) $\times$ spine subtype (thin, mushroom, stubby), $F_{(2,39)}=$ $0.83, p=0.44]$. Conversely, at the same time point in the shell, there was a significant increase in average thin spine density [Fig. 3B, $15 \%$ increase from 1.83 to 2.11 spines $/ \mu \mathrm{m}$, two-way ANOVA overall interaction, drug effect (cocaine, saline) $\times$ spine subtype (thin, mushroom, stubby), $F_{(2,39)}=7.66, p=0.002$; and thin spine density, $t_{(39)}=4.53, p<$ 0.001 ], with no changes in mushroom

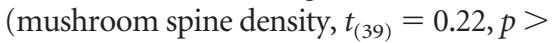
0.05 ) or stubby (stubby spine density, $t_{(39)}=$ $0.63, p>0.05)$ spines.

At $24 \mathrm{~h}$ of cocaine withdrawal, proximal spine density in NAc core was decreased by a selective loss of thin spines [Fig. 3C, 13\% decrease from 2.83 to 2.46 spines/ $\mu \mathrm{m}$, twoway ANOVA overall interaction, drug effect (cocaine, saline) $\times$ spine subtype (thin, mushroom, stubby), $F_{(2,39)}=4.43, p=$ 0.02 , and thin spine density, $t_{(39)}=3.97, p<$ 0.001 ], whereas proximal spine density in the shell was increased by a selective addition of new thin spines [Fig. 3D, 20\% increase from 1.86 to 2.23 spines/ $\mu \mathrm{m}$, two-way ANOVA overall interaction, drug effect (cocaine, saline) $\times$ spine subtype (thin, mushroom, stubby), $F_{(2,39)}=$ 7.55, $p=0.002$, and thin spine density, $\left.t_{(39)}=4.79, p<0.001\right]$.
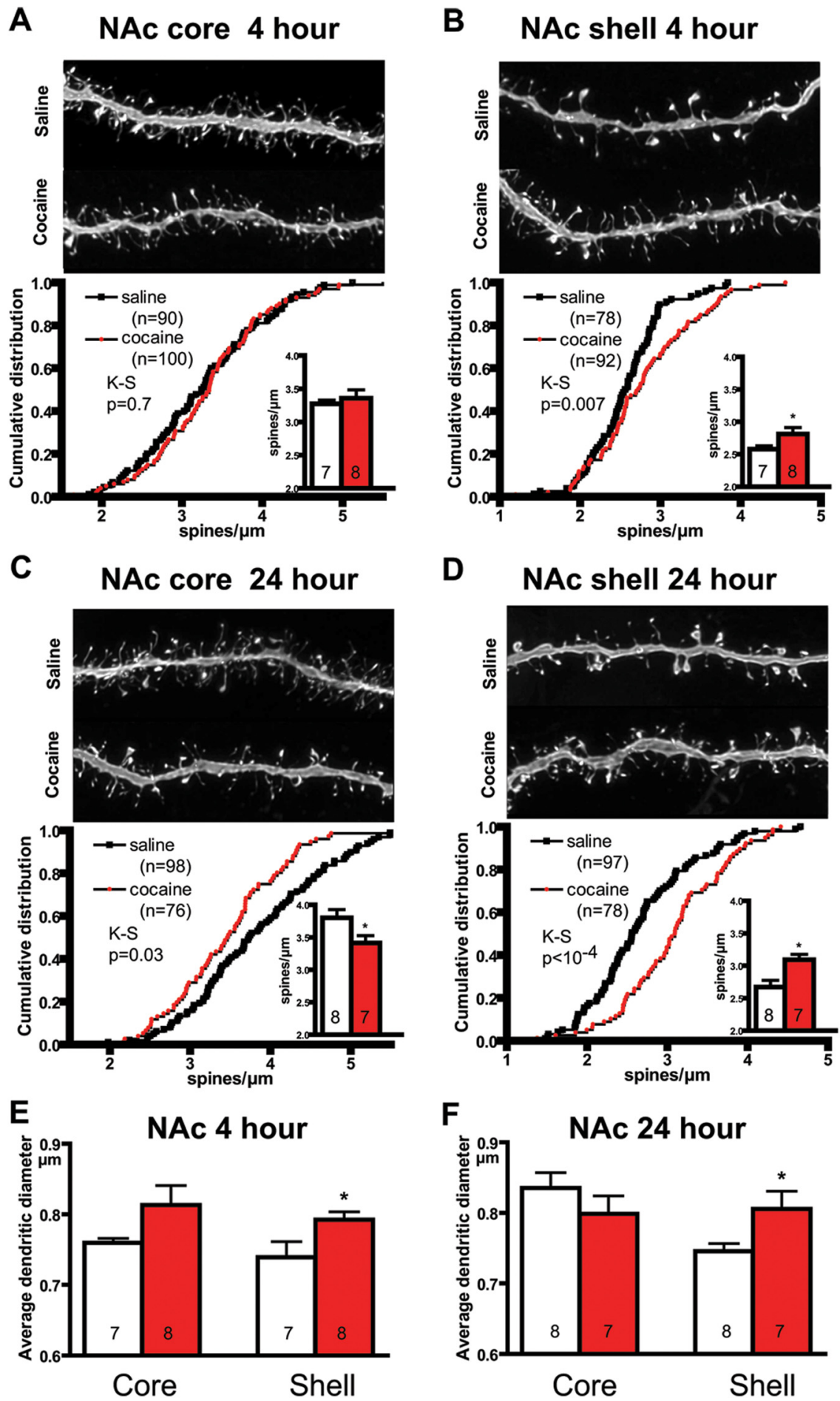

Figure 2. Proximal dendritic spine density and diameter are differentially regulated by cocaine in NAc core versus shell 4 and $24 \mathrm{~h}$ after the last injection. $\boldsymbol{A}-\boldsymbol{D}$, Top images show representative projected $z$-stacks from each experimental group. Cumulative frequencies are plotted using each analyzed dendrite from all animals in a group. Inset bar graphs show the average proximal spine density calculated per animal and then per group. $A, B, A t 4 h$, cocaine significantly increases proximal spine density in the shell but not core. $C, D, A t 24 \mathrm{~h}$, cocaine significantly decreases proximal spine density in the core and increases proximal spine density in the shell. $\boldsymbol{E}, \boldsymbol{F}$, Average proximal dendrite diameter is significantly increased in the shell at both 4 and $24 \mathrm{~h}$ after the last cocaine injection with a trend for an increase in the NAc core at $4 \mathrm{~h} . \mathrm{K}-\mathrm{S}$ test, ${ }^{*} p<0.05$.
Chronic cocaine differentially regulates proximal spine subtype head diameter

Because spine size is correlated with synaptic strength (Bourne and Harris, 2007), we next investigated the effect of cocaine on the head diameter of the two most prominent spine types: thin and mushroom. At $4 \mathrm{~h}$ of cocaine withdrawal, proximal mushroom spine head diameter was unaffected in NAc core and shell, in terms of both overall distribution (Fig. $3 E, F, \mathrm{~K}-\mathrm{S}$ test, $p=0.42$ and $p=0.13$ in core and shell, respectively) and frequency of spines at individual $0.1 \mu \mathrm{m}$ bins [Fig. $3 E, F$, two-way repeated- 
Spine subtype density
A
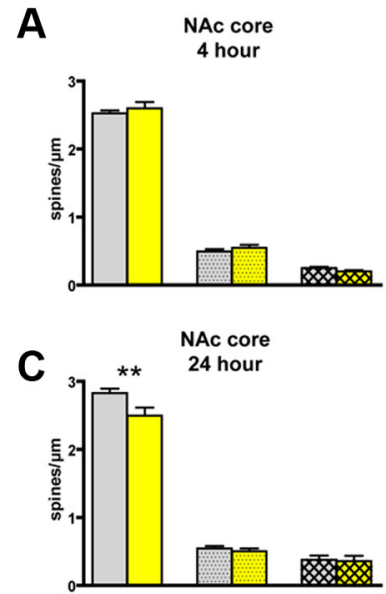

B

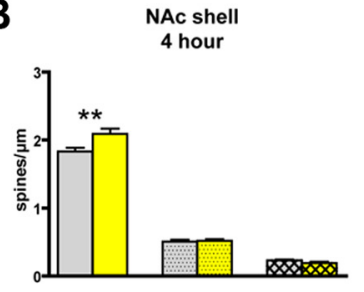

D

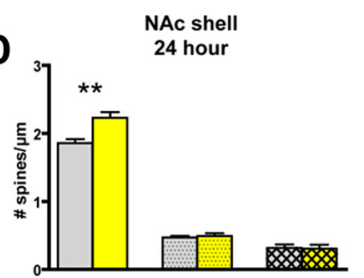

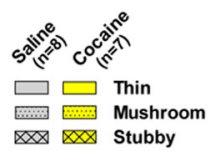

Spine subtype head diameter
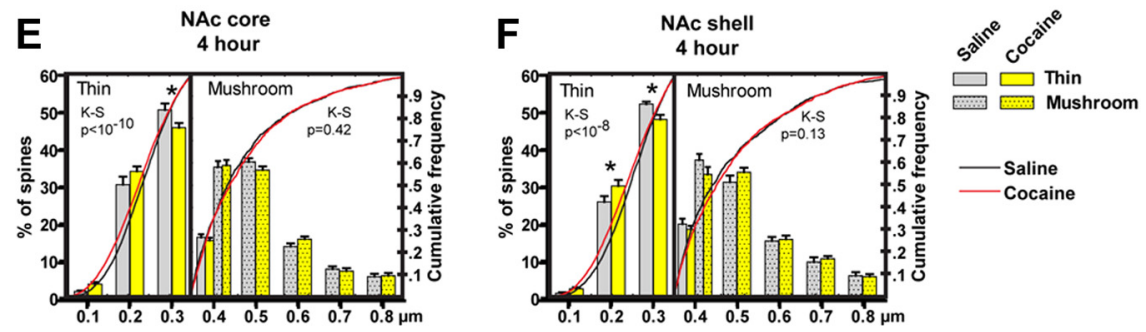
Saline
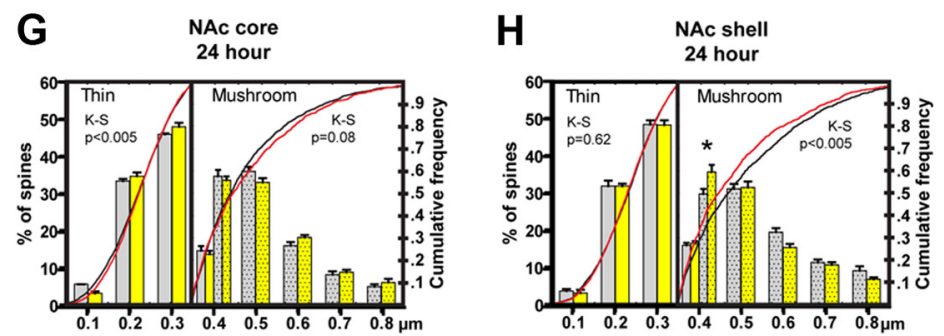

Figure 3. Cocaine selectively and oppositely regulates thin dendritic spine density and morphology in the proximal dendrites of NAc core and shell. $\boldsymbol{A}-\boldsymbol{D}$, Spine subtype densities based on an unbiased classifier in the core versus shell at 4 or $24 \mathrm{~h}$ after the last cocaine injection. $A, B, A t 4 \mathrm{~h}$, proximal thin spine density is selectively and significantly upregulated by cocaine in shell but not core. $\boldsymbol{C}, \mathbf{D}$, At $24 \mathrm{~h}$, cocaine significantly downregulates proximal thin spine density in the core, whereas the upregulation of thin spines in the shell is maintained. $\boldsymbol{E}-\boldsymbol{H}$, The spine head diameters of proximal thin and mushroom spines are plotted next to each other as cumulative distributions superimposed onto frequency plots in which the spines were binned by size first per animal and then by group using $0.1 \mu \mathrm{m}$ bins (numbers below bar graph represent lower bound of bin). $\boldsymbol{E}, \boldsymbol{F}$, At $4 \mathrm{~h}$, the cumulative frequencies of proximal thin spine head diameters in both core and shell are significantly left shifted. Binned data show a significant decrease in the frequency of thin spines with head diameters between 0.3 and $0.4 \mu \mathrm{m}$ in both subregions and a significant increase in smaller thin spines in the shell. There is no change in the size of mushroom spines at this time point. $\mathbf{G}, \boldsymbol{H}$, At $24 \mathrm{~h}$, the cumulative frequency of proximal thin spine head diameters is slightly but significantly right shifted in the core and unchanged in the shell. Binned data do not point to changes in frequency in any particular bin in the core. Interestingly, although mushroom spine size remains unaffected in the core, the cumulative frequency of the mushroom spine head diameter in the shell is significantly left shifted, which can be attributed to a selective increase in the smallest mushroom spines. $\mathrm{K}-\mathrm{S}$ test, ${ }^{*} p<0.05,{ }^{* *} p<0.001$.

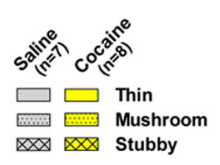

proximal thin spines between 0.3 and 0.4 $\mu \mathrm{m}$ in diameter [Fig. 3F, two-way repeated measures ANOVA overall interaction, drug effect (cocaine, saline) $\times$ bin $(0.1$, $0.2,0.3,0.4) F_{(3,39)}=3.874, p=0.016$ and bin $0.3, t_{(39)}=2.588, p>0.05$ ] was also accompanied by a significant increase in the frequency of smaller thin spines (Fig. $3 F$, bin $\left.0.2, t_{(39)}=2.719, p<0.05\right)$. Note that, when combined with the opposing regulation of thin spine density reported above, the leftward shift in proximal thin spine head diameter suggests a shrinking in the size of proximal thin spines in the core and the addition of new, small proximal thin spines in the shell. Importantly, at this time point, cocaine withdrawal effects on both proximal density and size are restricted to thin spines.

Interestingly, at $24 \mathrm{~h}$, proximal thin spine head diameter in the core was significantly right shifted (Fig. 3G, K-S test, $p<$ 0.005). Although this shift is subtle and does not reach significance at any individual bin [Fig. 3G, two-way repeated-measures ANOVA, no overall interaction, drug effect (cocaine, saline $) \times$ bin $(0.1,0.2,0.3,0.4)$, $F_{(3,39)}=1.178, p=0.33$ ], when combined with the loss of thin spines at this time point, it likely reflects the specific elimination of the smallest thin spines. Core proximal mushroom spines remain unaffected [Fig. 3G, K-S test, $p=0.08$ and two-way repeated-measures ANOVA, no overall interaction, drug effect (cocaine, saline $) \times$ bin $(0.4,0.5,0.6,0.7,0.85)$, $\left.F_{(4,52)}=1.570, p=0.20\right]$.

In contrast, in the shell after $24 \mathrm{~h}$ of withdrawal, the newly sprouted proximal thin spines exhibited control head diameters as indicated by a continued increase in thin spine density (see above) in the absence of a difference in size [Fig. $3 \mathrm{H}$, $\mathrm{K}-\mathrm{S}$ test, $p=0.62$ and two-way repeatedmeasures ANOVA, no overall interaction, drug effect (cocaine, saline) $\times$ bin $(0.1$, $\left.0.2,0.3,0.4), F_{(3,39)}=0.07440, p=0.97\right]$. However, the shell showed a leftward shift in proximal mushroom spine head diameter (Fig. $3 H, \mathrm{~K}-\mathrm{S}$ test, $p<0.005$ ). Because this shift can be attributed to a selective increase in the frequency of the measures ANOVA, no overall interaction, drug effect (cocaine, saline $) \times \operatorname{bin}(0.4,0.5,0.6,0.7,0.85), F_{(4,52)}=0.9619, p=0.44$ and $F_{(4,52)}=1.344, p=0.27$ in core and shell, respectively]. However, the head diameter of proximal thin spines was significantly left shifted in response to cocaine withdrawal, i.e., toward smaller sizes, in both core and shell (Fig. $3 E, F, \mathrm{~K}-\mathrm{S}$ test, $p<10^{-10}$ and $p<10^{-8}$, respectively). In the core, the overall distribution shift can be attributed to a significant decrease in the frequency of thin spines that are between 0.3 and $0.4 \mu \mathrm{m}$ in diameter [Fig. 3E, two-way repeatedmeasures ANOVA, overall interaction, drug effect (cocaine, saline $) \times \operatorname{bin}(0.1,0.2,0.3,0.4), F_{(3,39)}=3.251, p=0.03$ and bin 0.3 , $\left.t_{(39)}=2.715, p<0.05\right]$. In the shell, a similar decrease in frequency of smallest mushroom spines, i.e., those between 0.4 and $0.5 \mu \mathrm{m}$ in diameter [Fig. $3 H$, two-way repeated measures ANOVA, overall interaction, drug effect (cocaine, saline) $\times$ bin $(0.4,0.5,0.6,0.7$, $0.85), F_{(4,52)}=4.168, p=0.005$ and bin $0.4, t_{(52)}=3.523, p<$ $0.01]$, this likely indicates a conversion of thin spines into mushroom spines.

\section{Extended withdrawal from chronic cocaine results in a prolonged decrease in proximal thin spine density in the NAc core selectively}

Next, we asked which of any of the above effects on proximal spine density and size remain after prolonged withdrawal from 
cocaine. To ensure robust neuroplastic changes, we chose a commonly used $28 \mathrm{~d}$ injection paradigm, followed by $28 \mathrm{~d}$ of withdrawal. Therefore, it is important to note the possibility that greater total cocaine intake rather than longer withdrawal might be responsible for the results observed here. To our surprise, proximal spine density in the NAc core was decreased in this group too (Fig. $4 A$, inset, $16 \%$ decrease from $3.17 \pm 0.07$ to $2.67 \pm$ 0.07 spines $/ \mu \mathrm{m}, t$ test, $p=0.002$ ), matching our observations at the $24 \mathrm{~h}$ time point, whereas proximal spine density in the shell showed no change (Fig. $4 B$, inset, $t$ test, $p=0.26$ ). Cumulative distribution plots of proximal spine densities along individual dendrites indicated that spine elimination is uniform among sampled neurites in the core, with the leftward shift highly significant (Fig. $4 A, \mathrm{~K}-\mathrm{S}$ test, $p<$ $0.0008)$. In contrast, in the shell, there was no distribution change in proximal spine densities of individual sampled dendrites (Fig. $4 B, \mathrm{~K}-\mathrm{S}$ test, $p=0.29$ ).

Similar to the withdrawal time points examined after shorter periods of cocaine administration, the effect on core proximal spine density after a 1-month-long withdrawal from more prolonged cocaine administration was restricted to a selective reduction in thin and mushroom spines [Fig. $4 C$, two-way ANOVA, overall interaction, drug effect (cocaine, saline) $\times$ spine subtype (thin, mushroom, stubby), $F_{(2,24)}=14.34, p<$ 0.0001 ; thin spines, $16 \%$ decrease from $2.18 \pm 0.01$ to $1.83 \pm 0.07$ spines $/ \mu \mathrm{m}, t_{(24)}=7.986, p<0.001$; and mushroom spines, $15.7 \%$ decrease from $0.81 \pm 0.02$ to $0.68 \pm 0.02$ spines $/ \mu \mathrm{m}$, $\left.t_{(24)}=2.907, p<0.05\right]$, whereas no changes in the densities of any spine type was observed in the shell [Fig. 4D, two-way ANOVA, no overall interaction, drug effect (cocaine, saline) $\times$ spine subtype (thin, mushroom, stubby), $\left.F_{(2,24)}=0.566 p=0.58\right]$. No significant changes in proximal dendritic diameter or size of any spine subtype in either subregion were observed at this time point (data not shown).

Cocaine-induced neuroplasticity at dendritic tips does not follow the same pattern as the proximal spine morphometric changes

The surprising data from proximal dendrites, in combination with the fact that most if not all previous studies of cocaineinduced spine changes have focused on dendritic tips, necessitated an investigation of neuroplastic changes for dendritic tips in our model. For this purpose, we returned to the same neurons from which proximal dendrites were sampled and imaged one dendritic tip per neuron (Fig. $5 A$ ). No changes in spine density could be appreciated in distal dendrites in either core (Fig. $5 B$, $2.66 \pm 0.14$ vs $2.75 \pm 0.09$ in saline-treated vs cocaine-treated animals, $t$ test, $p=0.56$ ) or shell (Fig. $5 C, 2.28 \pm 0.0 .06$ vs $2.30 \pm$ 0.06 in saline-treated vs cocaine-treated animals, $t$ test, $p=0.88$ ) at $4 \mathrm{~h}$ of withdrawal from 1 week of cocaine exposure. At $24 \mathrm{~h}$, there was no difference in distal spine density in the core (Fig. $5 D$, $2.70 \pm 0.13$ vs $2.81 \pm 0.13$ in saline-treated vs cocaine-treated animals, $t$ test, $p=0.55)$, but a significant increase was observed in the shell (Fig. $5 E, 17 \%$ increase, from $2.18 \pm 0.06$ to $2.54 \pm$
B NAc shell 28 day
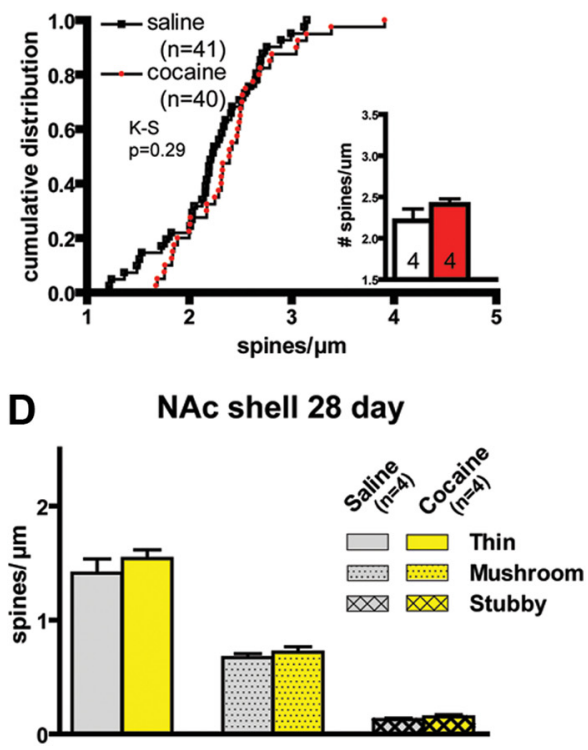

Figure 4. Downregulation of proximal NAc core thin dendritic spine density persists after $28 \mathrm{~d}$ of withdrawal from chronic The downregulation of proximal spines in the core continues to be selective for a loss of thin spines. $D$, No changes in the density of any proximal spine subtype are observed in the shell. K-S test, ${ }^{*} p<0.05,{ }^{* *} p<0.001$.

0.08 in saline-treated vs cocaine-treated animals, $t$ test, $p=$ 0.003). Consistent with the effect on proximal spine density, the increased spine density on shell dendritic tips was attributable to a selective increase in thin spines [18\% increase from 1.67 to 1.98 spines $/ \mu \mathrm{m}$, two-way ANOVA, overall interaction, drug effect (cocaine, saline) $\times$ spine subtype (thin, mushroom, stubby), $F_{(2,39)}=8.405, p=0.0009$, and thin spine density, $t_{(39)}=5.481$, $p<0.001$; data not shown]. No prolonged effects on distal spine density were observed at $28 \mathrm{~d}$ of withdrawal from $28 \mathrm{~d}$ of cocaine exposure in either core (Fig. $5 F, 2.74 \pm 0.14$ vs $2.69 \pm 0.18$ in saline-treated vs cocaine-treated animals, $t$ test, $p=0.82$ ) or shell (Fig. $5 G, 2.05 \pm 0.05$ vs $2.07 \pm 0.15$ in saline-treated vs cocainetreated animals, $t$ test, $p=0.88$ ). Also, tip dendrite diameter did not differ between saline and cocaine groups in either core or shell at any time point ( $t$ test, $p>0.2$ for all regions and time points; data not shown).

\section{Discussion}

\section{Summary of findings}

The present study demonstrates a striking divergence in cocaine regulation of dendritic spines at two levels of NAc microcircuitry: (1) core versus shell subregions and (2) proximal versus distal dendrites. Observed changes were restricted to thin spines, the class of spine shown to be highly motile and plastic (Kasai et al., 2010), whereas mushroom spines remained stable. Although it has been shown by others (Arellano et al., 2007) and us (Dumitriu et al., 2011) that spine size lies on a continuum, the usefulness of spine classification has nonetheless been clearly demonstrated by studies implicating thin spines as behaviorally relevant in paradigms such as learning (Moser et al., 1994; Dumitriu et al., 2010) and cocaine addiction (Shen et al., 2009; LaPlant et al., 2010). Additionally, we report drug-induced regulation of proximal dendritic diameter, potentially identifying a novel mediator of changes in signal propagation, since dendritic diameter-via its 
A

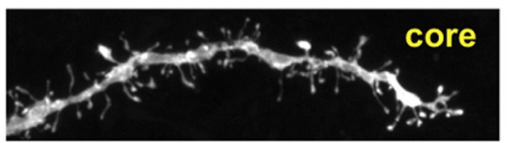

B

NAc core - dendritic tip

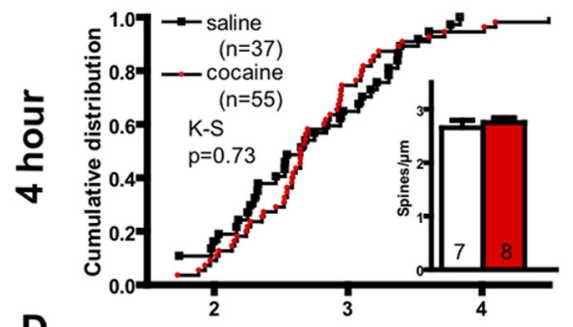

D

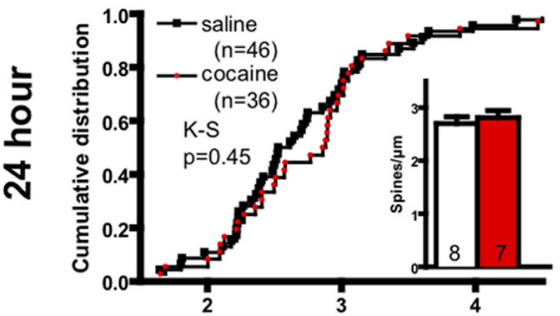

$\mathbf{F}$

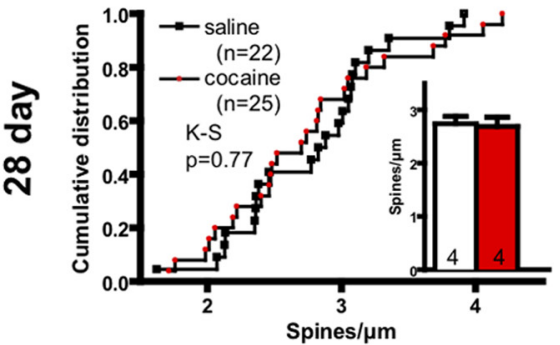

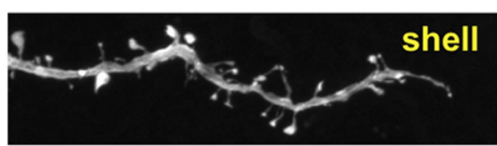

NAc shell - dendritic tip

C

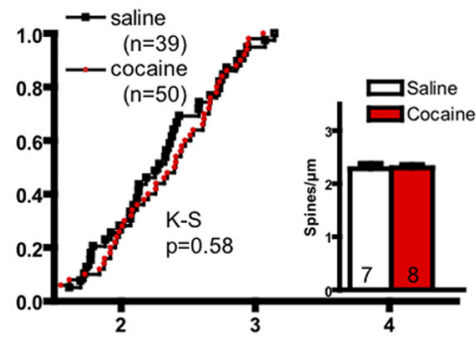

$\mathbf{E}$

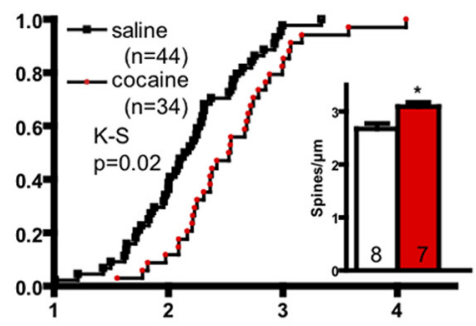

G

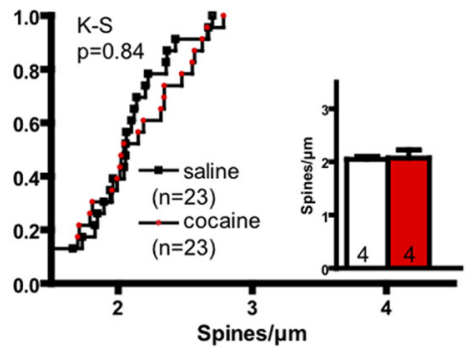

Figure 5. Distal dendritic spine density regulation by cocaine in NAc core versus shell $4 \mathrm{~h}, 24 \mathrm{~h}$, and $28 \mathrm{~d}$ after the last injection. $\boldsymbol{A}$, Images show representative projected $z$-stacks from dendritic tips in the core and shell. $\boldsymbol{B}$ - $\mathbf{G}$, Cumulative frequencies are plotted using each analyzed dendrite from all animals in a group. Inset bar graphs show the average spine density calculated per animal and then per group. $\boldsymbol{B}, \boldsymbol{C}$, At $4 \mathrm{~h}$, cocaine does not regulate distal spine density in either the core or the shell. $\boldsymbol{D}, \boldsymbol{E}, \mathrm{At} 24 \mathrm{~h}$, cocaine significantly increases distal spine density in the shell with no effect in the core. $\boldsymbol{F}, \mathbf{G}$, After $28 \mathrm{~d}$ of withdrawal, cocaine does not regulate distal spine density in the core or shell. K-S test, ${ }^{*} p<0.05$.

action on input impedance-can significantly affect properties of synaptic inputs (Holmes, 1989; Branco et al., 2010).

\section{Opposing effects on core versus shell proximal spines}

A main finding presented here is the opposing effects of cocaine on proximal spines within the two NAc subregions (Fig. 6). Spines are upregulated in shell but downregulated in core. The time course of these events differs. After $7 \mathrm{~d}$ of cocaine administration, new spines sprout in shell within $4 \mathrm{~h}$, whereas spine elimination in core requires $24 \mathrm{~h}$. To investigate long-lasting changes in spine density, we used a separate paradigm of $28 \mathrm{~d}$ of cocaine administration followed by $28 \mathrm{~d}$ of withdrawal and found no difference in drug-treated versus saline-treated animals in shell. In contrast, elimination of proximal spines in core was also found in this prolonged paradigm, suggesting that cocaine-induced spine plasticity is more enduring in core than shell.

While the observed decreased spine density in NAc core is novel, core/shell divergence is not. Although several groups have shown concerted core/shell spine changes after cocaine administration in rats (Norrholm et al., 2003; Li et al., 2004; Ferrario et al., 2005), a report in mice showed increased spine density in shell but not core (Martin et al., 2011). There are many potential sources for these differences, including species, drug dose, and drug administration paradigm. For example, Li et al. (2004) showed that the increased spine density in core correlates with psychomotor sensitization and is restricted to animals that are administered cocaine in a novel environment. Thus, it is possible that our results would have shown a different pattern of spine changes with animals injected in a novel environment rather than their home cages.

Another potential source of variability comes from differences in spine counting methods (for an in-depth discussion, see Materials and Methods). In the only previous report of psychostimulant-mediated effects on MSNs using 3D measures, spine density in rat NAc core did not change after 3 weeks of withdrawal from 1 week of cocaine administration; this group did not examine the shell (Shen et al., 2009). In contrast, we used a 28 d injection paradigm, followed by $28 \mathrm{~d}$ of withdrawal. Therefore, it is possible that persistent downregulation of spines in the NAc core is contingent on the duration of cocaine treatment. This is a particularly attractive hypothesis given that, although Shen et al. (2009) did not observe an overall difference in spine density, they did report a small but significant cocaineinduced decrease in thin spines.

The enduring spine density change in core but not shell fits well with the established idea that the shell is preferentially involved in the development of addiction, whereas the core mediates the long-term execution of learned addiction-related behaviors (Di Chiara, 2002; Ito et al., 2004; Meredith et al., 2008). Consistent with the idea of the NAc core being the locus of long-lasting drug-induced neuroplasticity, several studies have shown that electrophysiological changes in core persist longer than their shell counterparts. For example, LTD is inhibited in both core and shell after $1 \mathrm{~d}$ of cocaine withdrawal, but this adaptation is maintained only in core after $21 \mathrm{~d}$ of withdrawal (Martin et al., 2006). In addition, core but not shell MSNs exhibit enhanced stimulus-induced single-unit activity in vivo after 1 month of withdrawal (Hollander and Carelli, 2007).

There in an interesting parallel between our early withdrawal data and a recent report on the effect of cocaine on intrinsic membrane excitability. Generally, cocaine is thought to decrease MSN excitability. However, most studies have used either combined core/shell preparations or focused specifically on shell (Wolf, 2010). Kourrich and Thomas (2009), using a drug treatment paradigm similar to ours, showed that cocaine decreases excitability of mouse shell MSNs but increases it in core at $24 \mathrm{~h}$ of withdrawal. Because our observed spine density changes would predict an opposite effect on the drive of MSNs (increased in shell and decreased in core), two possibilities exist: spine regulation might reflect a compensatory mechanism that protects the MSNs from changes in excitability, or changes in spine density (and 
Core

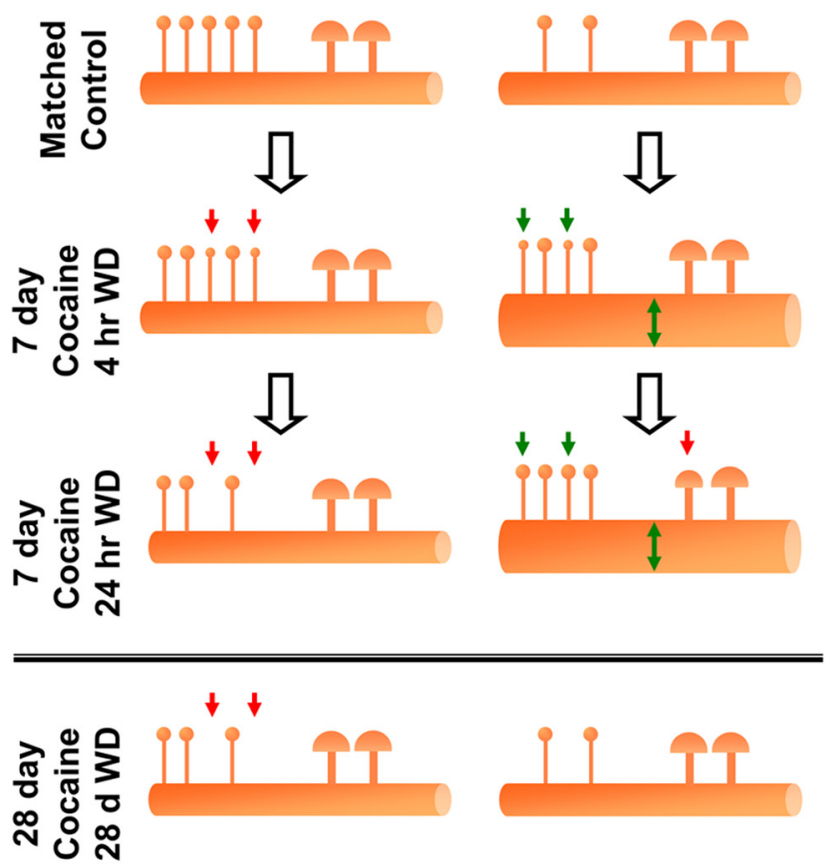

Shell

\begin{tabular}{|l|c|c|c|c|c|c|}
\cline { 2 - 7 } \multicolumn{1}{c|}{} & \multicolumn{3}{|c|}{ Core } & \multicolumn{3}{c|}{ Shell } \\
\cline { 2 - 7 } & $\begin{array}{c}4 \\
\mathrm{hr}\end{array}$ & $\begin{array}{c}\mathbf{2 4} \\
\mathrm{hr}\end{array}$ & $\begin{array}{c}\mathbf{2 8} \\
\mathrm{d}\end{array}$ & $\begin{array}{c}4 \\
\mathrm{hr}\end{array}$ & $\begin{array}{c}\mathbf{2 4} \\
\mathrm{hr}\end{array}$ & $\begin{array}{c}\mathbf{2 8} \\
\mathrm{d}\end{array}$ \\
\hline $\begin{array}{l}\text { Total spine } \\
\text { density }\end{array}$ & 0 & $\downarrow$ & $\downarrow$ & $\uparrow$ & $\uparrow$ & 0 \\
\hline $\begin{array}{l}\text { Thin spine } \\
\text { density }\end{array}$ & 0 & $\downarrow$ & $\downarrow$ & $\uparrow$ & $\uparrow$ & 0 \\
\hline $\begin{array}{l}\text { Mushroom } \\
\text { density }\end{array}$ & 0 & 0 & 0 & 0 & 0 & 0 \\
\hline $\begin{array}{l}\text { Thin spine } \\
\text { head diameter }\end{array}$ & $\downarrow$ & $\uparrow$ & 0 & $\downarrow$ & 0 & 0 \\
\hline $\begin{array}{l}\text { Mushroom } \\
\text { head diameter }\end{array}$ & 0 & 0 & 0 & 0 & $\downarrow$ & 0 \\
\hline $\begin{array}{l}\text { Dendrite } \\
\text { diameter }\end{array}$ & 0 & 0 & 0 & $\uparrow$ & $\uparrow$ & 0 \\
\hline Firing rate & $\mathrm{n} / \mathrm{a}$ & $\uparrow *$ & $\mathrm{n} / \mathrm{a}$ & $\mathrm{n} / \mathrm{a}$ & $\downarrow *$ & $\mathrm{n} / \mathrm{a}$ \\
\hline $\begin{array}{l}\text { AMPA/NMDA } \\
\text { ratio* }\end{array}$ & $\mathrm{n} / \mathrm{a}$ & $\downarrow *$ & $\mathrm{n} / \mathrm{a}$ & $\mathrm{n} / \mathrm{a}$ & $\downarrow *$ & $\mathrm{n} / \mathrm{a}$ \\
\hline
\end{tabular}

Figure 6. Summary diagram and table of the effects of chronic cocaine on proximal dendritic spine morphometrics. In the NAc core, chronic cocaine decreases proximal dendritic spine head diameter at $4 \mathrm{~h}$ and by $24 \mathrm{~h}$ causes a selective elimination of thin spines that is maintained for up to 1 month. Conversely, in the NAc shell, which at baseline has fewer proximal thin spines than the core, new thin spines are formed by $4 \mathrm{~h}$ and maintained for up to $24 \mathrm{~h}$. There is also an increase in proximal dendritic diameter in the shell. However, unlike the core, the changes that occur in the shell are transient because they are not observed after prolonged withdrawal from cocaine. Red arrows indicate shrinkage or elimination, and green arrows indicate growth or sprouting. ${ }^{*}$ Data adapted from Kourrich and Thomas (2009).

hence changes in MSN drive) lead to a homeostatic tuning of cell excitability. Support for the latter is offered from data demonstrating homeostatic increases in excitability of striatal MSNs after downregulation of spine density in response to dopamine depletion (Azdad et al., 2009). Others have also demonstrated co-regulation of synaptic and homeostatic plasticity of striatal MSNs after cocaine withdrawal (Ishikawa et al., 2009; Huang et al., 2011).

How do our data relate to cocaine-induced changes in synaptic strength? It is generally accepted that cocaine withdrawal globally increases NAc MSN synaptic strength via upregulation of glutamatergic AMPA receptors, although interestingly this occurs slowly, with no change apparent at $24 \mathrm{~h}$ but significant upregulation at $21 \mathrm{~d}$ (Wolf and Ferrario, 2010). Furthermore, at $24 \mathrm{~h}$, an increase in silent synapses has been observed in the shell (Huang et al., 2009), possibly a reflection of the new thin spines we observed here. Once again, however, direct comparison with our data leads to the fundamental problem that most studies on glutamatergic receptors have used mixed core/shell preparations or focused on the shell, and therefore the extent to which these changes occur within each subregion remains essentially unknown (Wolf, 2010).

Is there evidence for a mechanism that could lead to synaptic downregulation selectively in NAc core? One possibility is dopamine, because cocaine withdrawal has been shown to decrease extracellular dopamine levels in NAc (Parsons et al., 1991; Baker et al., 2003). A unique feature of NAc is dual glutamatergic and dopaminergic innervation of individual spines, with the latter targeting the spine neck and thus ideally positioned to modulate cortical and limbic inputs (Sesack and Grace, 2010). This glutamate-dopamine convergence is significantly higher in core than shell (Zahm and Brog, 1992) and has been suggested to underlie the selective NAc core spine downregulation after unilateral dopamine depletion in vivo (Meredith et al., 1995).

\section{Differences in proximal versus distal spine regulation}

The second novel finding presented here is the dichotomy in proximal versus distal cocaine-induced spine regulation. In contrast to our observations for proximal dendrites (defined as the middle portions of terminal dendrites), after $24 \mathrm{~h}$ of cocaine withdrawal, distal spine density in core was unchanged, whereas an increase in thin spine density was appreciated in shell. Our prolonged treatment and withdrawal paradigm failed to alter distal spine density in either subregion. Combined, these findings suggest that cocaine withdrawal induces global increases in dendritic spines in shell but compartment-specific spine elimination in core.

A fundamental topography of inputs to MSNs has been known for decades, with proximal dendrites receiving shaft connections from within NAc and distal dendrites receiving long range projections from cortex, hippocampus, and amygdala onto dendritic spines (Smith and Bolam, 1990). However, no spine-specific topography of cortical and limbic connections has been identified to date, although nonrandom patterns have been suggested (O'Donnell et al., 1999). Morphological (French and Totterdell, 2002; French and Totterdell, 2003) and electrophysiological (O'Donnell and Grace, 1995) studies have demonstrated substantial long-range input convergence onto individual cells, and recent work has demonstrated at least a functional dichotomy in MSN spines from different dendritic subregions. Distal, but not proximal, spines have the capability of creating up states in vitro (Plotkin et al., 2011), leading to the hypothesis that different MSN dendritic compartments serve different roles 
and perhaps receive different inputs. The idea of active dendritic compartments and ability of dendrites to perform complex computations is well supported in other brain regions (Poirazi and Mel, 2001; Poirazi et al., 2003; Branco and Häusser, 2010; Branco and Häusser, 2011). Future experiments, selectively targeting inputs from identified regions (e.g., with optogenetics), are paramount for tackling the important question of the presynaptic origin of cocaineinduced spine plasticity.

\section{Implications of multilevel divergence in spine regulation}

Perhaps the most compelling finding of the present study is not within the details of cocaine-induced spine plasticity but rather the complex nature of this regulation. Our data highlight the importance of studying specific components of the microcircuitry as independent structures. Furthermore, data presented here support the idea that NAc shell is preferentially involved in immediate drug reward, whereas the core might play a more explicit role in longer-term aspects of addiction.

\section{References}

Arellano JI, Benavides-Piccione R, Defelipe J, Yuste R (2007) Ultrastructure of dendritic spines: correlation between synaptic and spine morphologies. Front Neurosci 1:131-143.

Azdad K, Chàvez M, Don Bischop P, Wetzelaer P, Marescau B, De Deyn PP, Gall D, Schiffmann SN (2009) Homeostatic plasticity of striatal neurons intrinsic excitability following dopamine depletion. PLoS One 4:e6908.

Baker DA, McFarland K, Lake RW, Shen H, Tang XC, Toda S, Kalivas PW (2003) Neuroadaptations in cystine-glutamate exchange underlie cocaine relapse. Nat Neurosci 6:743-749.

Bourne J, Harris KM (2007) Do thin spines learn to be mushroom spines that remember? Curr Opin Neurobiol 17:381-386.

Branco T, Häusser M (2010) The single dendritic branch as a fundamental functional unit in the nervous system. Curr Opin Neurobiol 20:494-502.

Branco T, Häusser M (2011) Synaptic integration gradients in single cortical pyramidal cell dendrites. Neuron 69:885-892.

Branco T, Clark BA, Häusser M (2010) Dendritic discrimination of temporal input sequences in cortical neurons. Science 329:1671-1675.

Di Chiara G (2002) Nucleus accumbens shell and core dopamine: differential role in behavior and addiction. Behav Brain Res 137:75-114.

Dobi A, Seabold GK, Christensen CH, Bock R, Alvarez VA (2011) Cocaineinduced plasticity in the nucleus accumbens is cell specific and develops without prolonged withdrawal. J Neurosci 31:1895-1904.

Dumitriu D, Hao J, Hara Y, Kaufmann J, Janssen WG, Lou W, Rapp PR, Morrison JH (2010) Selective changes in thin spine density and morphology in monkey prefrontal cortex correlate with aging-related cognitive impairment. J Neurosci 30:7507-7515.

Dumitriu D, Rodriguez A, Morrison JH (2011) High-throughput, detailed, cell-specific neuroanatomy of dendritic spines using microinjection and confocal microscopy. Nat Protoc 6:1391-1411.

Ferrario CR, Gorny G, Crombag HS, Li Y, Kolb B, Robinson TE (2005) Neural and behavioral plasticity associated with the transition from controlled to escalated cocaine use. Biol Psychiatry 58:751-759.

French SJ, Totterdell S (2002) Hippocampal and prefrontal cortical inputs monosynaptically converge with individual projection neurons of the nucleus accumbens. J Comp Neurol 446:151-165.

French SJ, Totterdell S (2003) Individual nucleus accumbens-projection neurons receive both basolateral amygdala and ventral subicular afferents in rats. Neuroscience 119:19-31.

Hama K, Arii T, Kosaka T (1989) Three-dimensional morphometrical study of dendritic spines of the granule cell in the rat dentate gyrus with HVEM stereo images. J Electron Microsc Tech 12:80-87.

Hollander JA, Carelli RM (2007) Cocaine-associated stimuli increase cocaine seeking and activate accumbens core neurons after abstinence. J Neurosci 27:3535-3539.

Holmes WR (1989) The role of dendritic diameters in maximizing the effectiveness of synaptic inputs. Brain Res 478:127-137.

Huang YH, Lin Y, Mu P, Lee BR, Brown TE, Wayman G, Marie H, Liu W, Yan Z, Sorg BA, Schlüter OM, Zukin RS, Dong Y (2009) In vivo cocaine experience generates silent synapses. Neuron 63:40-47.

Huang YH, Schlüter OM, Dong Y (2011) Cocaine-induced homeostatic regulation and dysregulation of nucleus accumbens neurons. Behav Brain Res 216:9-18.

Ishikawa M, Mu P, Moyer JT, Wolf JA, Quock RM, Davies NM, Hu XT, Schlüter OM, Dong Y (2009) Homeostatic synapse-driven membrane plasticity in nucleus accumbens neurons. J Neurosci 29:5820-5831.

Ito R, Robbins TW, Everitt BJ (2004) Differential control over cocaineseeking behavior by nucleus accumbens core and shell. Nat Neurosci 7:389-397.

Kalivas PW (2009) The glutamate homeostasis hypothesis of addiction. Nat Rev Neurosci 10:561-572.

Kasai H, Fukuda M, Watanabe S, Hayashi-Takagi A, Noguchi J (2010) Structural dynamics of dendritic spines in memory and cognition. Trends Neurosci 33:121-129.

Kiraly DD, Ma XM, Mazzone CM, Xin X, Mains RE, Eipper BA (2010) Behavioral and morphological responses to cocaine require kalirin7. Biol Psychiatry 68:249-255.

Kourrich S, Thomas MJ (2009) Similar neurons, opposite adaptations: psychostimulant experience differentially alters firing properties in accumbens core versus shell. J Neurosci 29:12275-12283.

LaPlant Q, Vialou V, Covington HE 3rd, Dumitriu D, Feng J, Warren BL, Maze I, Dietz DM, Watts EL, Iñiguez SD, Koo JW, Mouzon E, Renthal W, Hollis F, Wang H, Noonan MA, Ren Y, Eisch AJ, Bolaños CA, Kabbaj M, Xiao G, Neve RL, Hurd YL, Oosting RS, Fan G, Morrison JH, Nestler EJ (2010) Dnmt3a regulates emotional behavior and spine plasticity in the nucleus accumbens. Nat Neurosci 13:1137-1143.

LaPlant Q, Nestler EJ (2011) CRACKing the histone code: cocaine's effects on chromatin structure and function. Horm Behav 59:321-330.

Larkum ME, Nevian T, Sandler M, Polsky A, Schiller J (2009) Synaptic integration in tuft dendrites of layer 5 pyramidal neurons: a new unifying principle. Science 325:756-760.

Lee KW, Kim Y, Kim AM, Helmin K, Nairn AC, Greengard P (2006) Cocaine-induced dendritic spine formation in D1 and D2 dopamine receptor-containing medium spiny neurons in nucleus accumbens. Proc Natl Acad Sci U S A 103:3399-3404.

Li Y, Kolb B, Robinson TE (2003) The location of persistent amphetamineinduced changes in the density of dendritic spines on medium spiny neurons in the nucleus accumbens and caudate-putamen. Neuropsychopharmacology 28:1082-1085.

Li Y, Acerbo MJ, Robinson TE (2004) The induction of behavioural sensitization is associated with cocaine-induced structural plasticity in the core (but not shell) of the nucleus accumbens. Eur J Neurosci 20:1647-1654.

Martin BJ, Naughton BJ, Thirtamara-Rajamani K, Yoon DJ, Han DD, Devries AC, Gu HH (2011) Dopamine transporter inhibition is necessary for cocaine-induced increases in dendritic spine density in the nucleus accumbens. Synapse 65:490-496.

Martin M, Chen BT, Hopf FW, Bowers MS, Bonci A (2006) Cocaine selfadministration selectively abolishes LTD in the core of the nucleus accumbens. Nat Neurosci 9:868-869.

Meredith GE, Ypma P, Zahm DS (1995) Effects of dopamine depletion on the morphology of medium spiny neurons in the shell and core of the rat nucleus accumbens. J Neurosci 15:3808-3820.

Meredith GE, Baldo BA, Andrezjewski ME, Kelley AE (2008) The structural basis for mapping behavior onto the ventral striatum and its subdivisions. Brain Struct Funct 213:17-27.

Moser MB, Trommald M, Andersen P (1994) An increase in dendritic spine density on hippocampal CA1 pyramidal cells following spatial learning in adult rats suggests the formation of new synapses. Proc Natl Acad Sci U S A 91:12673-12675.

Norrholm SD, Bibb JA, Nestler EJ, Ouimet CC, Taylor JR, Greengard P (2003) Cocaine-induced proliferation of dendritic spines in nucleus accumbens is dependent on the activity of cyclin-dependent kinase-5. Neuroscience 116:19-22.

O'Donnell P, Grace AA (1995) Synaptic interactions among excitatory afferents to nucleus accumbens neurons: hippocampal gating of prefrontal cortical input. J Neurosci 15:3622-3639.

O’Donnell P, Greene J, Pabello N, Lewis BL, Grace AA (1999) Modulation of cell firing in the nucleus accumbens. Ann N Y Acad Sci 877:157-175.

Parsons LH, Smith AD, Justice JB Jr (1991) Basal extracellular dopamine is decreased in the rat nucleus accumbens during abstinence from chronic cocaine. Synapse 9:60-65.

Paxinos G, Franklin KBJ (2001) The mouse brain in stereotaxic coordinates, Ed 2. New York: Academic 
Plotkin JL, Day M, Surmeier DJ (2011) Synaptically driven state transitions in distal dendrites of striatal spiny neurons. Nat Neurosci 14:881-888.

Poirazi P, Mel BW (2001) Impact of active dendrites and structural plasticity on the memory capacity of neural tissue. Neuron 29:779-796.

Poirazi P, Brannon T, Mel BW (2003) Pyramidal neuron as two-layer neural network. Neuron 37:989-999.

Pulipparacharuvil S, Renthal W, Hale CF, Taniguchi M, Xiao G, Kumar A, Russo SJ, Sikder D, Dewey CM, Davis MM, Greengard P, Nairn AC, Nestler EJ, Cowan CW (2008) Cocaine regulates MEF2 to control synaptic and behavioral plasticity. Neuron 59:621-633.

Renthal W, Kumar A, Xiao G, Wilkinson M, Covington HE 3rd, Maze I, Sikder D, Robison AJ, LaPlant Q, Dietz DM, Russo SJ, Vialou V, Chakravarty S, Kodadek TJ, Stack A, Kabbaj M, Nestler EJ (2009) Genomewide analysis of chromatin regulation by cocaine reveals a role for sirtuins. Neuron 62:335-348.

Robinson TE, Kolb B (1999) Alterations in the morphology of dendrites and dendritic spines in the nucleus accumbens and prefrontal cortex following repeated treatment with amphetamine or cocaine. Eur J Neurosci 11:1598-1604.

Rodriguez A, Ehlenberger DB, Dickstein DL, Hof PR, Wearne SL (2008) Automated three-dimensional detection and shape classification of dendritic spines from fluorescence microscopy images. PLoS One 3:e1997.

Russo SJ, Wilkinson MB, Mazei-Robison MS, Dietz DM, Maze I, Krishnan V, Renthal W, Graham A, Birnbaum SG, Green TA, Robison B, Lesselyong A, Perrotti LI, Bolaños CA, Kumar A, Clark MS, Neumaier JF, Neve RL, Bhakar AL, Barker PA, Nestler EJ (2009) Nuclear factor $\kappa$ B signaling regulates neuronal morphology and cocaine reward. J Neurosci 29:3529-3537.
Russo SJ, Dietz DM, Dumitriu D, Morrison JH, Malenka RC, Nestler EJ (2010) The addicted synapse: mechanisms of synaptic and structural plasticity in nucleus accumbens. Trends Neurosci 33:267-276.

Sesack SR, Grace AA (2010) Cortico-basal ganglia reward network: microcircuitry. Neuropsychopharmacology 35:27-47.

Shen HW, Toda S, Moussawi K, Bouknight A, Zahm DS, Kalivas PW (2009) Altered dendritic spine plasticity in cocaine-withdrawn rats. J Neurosci 29:2876-2884.

Smith AD, Bolam JP (1990) The neural network of the basal ganglia as revealed by the study of synaptic connections of identified neurones. Trends Neurosci 13:259-265.

Spruston N (2008) Pyramidal neurons: dendritic structure and synaptic integration. Nat Rev Neurosci 9:206-221.

Vecellio M, Schwaller B, Meyer M, Hunziker W, Celio MR (2000) Alterations in purkinje cell spines of calbindin D-28 k and parvalbumin knockout mice. Eur J Neurosci 12:945-954.

Wolf ME (2010) The Bermuda triangle of cocaine-induced neuroadaptations. Trends Neurosci 33:391-398.

Wolf ME, Ferrario CR (2010) AMPA receptor plasticity in the nucleus accumbens after repeated exposure to cocaine. Neurosci Biobehav Rev $35: 185-211$

Zahm DS (2000) An integrative neuroanatomical perspective on some subcortical substrates of adaptive responding with emphasis on the nucleus accumbens. Neurosci Biobehav Rev 24:85-105.

Zahm DS, Brog JS (1992) On the significance of subterritories in the "accumbens" part of the rat ventral striatum. Neuroscience 50:751-767. 